\title{
The representative model of teamwork adapted administrative management theory where leadership is owned exclusively by physician
}

\author{
Professor Valentina Zaharia PhD \\ Dimitrie Cantemir Christian University, Faculty of Marketing \\ Lecturer I. Donciu PhD \\ Faculty of Dentistry, UMF Bucharest \\ Lecturer M.Dogaru PhD \\ Dimitrie Cantemir Christian University, Faculty of Marketing \\ Email: mirela.dogaru@gmail.com \\ Asisstant V.Perianu PhD Student \\ Faculty of Dentistry, UMF Bucharest
}

\begin{abstract}
H. Fayol the organization as a complex organism that divides it into several parts, each part by executing specific operations, such as: technical (production), trade (supply, sale, exchange), financial records (accounting, statistics), security, insurance (Protection of property and persons) and administrative (foresight, organization, coordination, command and control).
\end{abstract}

Keywords: division of labor, discipline, leadership, teamwork.

JEL Classification: M120

\section{Introduction}

Henry Fayol (1941 - 1925)-develops administrative management theory is concerned with the industrial enterprise. The paper "General Administration et INDUSTRIAL" published by him in 1915, has so far remained a reference point throughout the world management theory (Huczynski, Buchanan, 2001). H. Fayla elaborates on the management principles of administrative organization, while managing to demonstrate that the management functions exists at all levels in the organization.

The principles of H. Fayol (Huczynski, Buchanan, 2001) are:

- The division of labor, leading to increased efficiency - contractors specializing in conducting operations. The purpose of the division of labor is the execution of works, higher volume and better quality in the same conditions. This is achieved by reducing the number of targets to be targeted attention and action. The result of the division of labor is the specialization of functions and power sharing; 
- Authority and responsibility - the right to give orders. Hierarchical authority managers resulting from their right to give orders, resolutions, make decisions, etc. achievement authority is correlated with assigned responsibilities;

- Discipline - the rules and regulations. Rules and norms that underlie the organization and functioning of the organization must be strictly observed. Their Violations entail sanctions. Discipline requires meeting and respecting the agreements reached between the organization and its workers;

- Unity of command and action - performer receives provisions from one manager;

- Steering unit - a boss and a plan for a group. Ordering, directing and coordinating efforts organization members are tasks of a single senior manager;

- The general subordination of individual interests - individual interests are subordinated to general. The interests of an individual or group of individuals should not be above the interests of the organization;

- Fair remuneration of staff - salary for the work performed. In order to ensure loyalty and support workers, they must receive a fair wage for their work;

- Centralization and decentralization - the balance of centralization - decentralization. There must be at a level that ensures sufficient authority to subordinates tasks proper performance of their duties. As the division of labor, centralization is a natural phenomenon, the balance between centralization and decentralization depending on specific conditions;

- Hierarchy - line authority from the top to the bottom. Authority is reduced along the path of top manager and the lower level of the organization. Scalar chain is the range of persons occupying positions of management, from the top of the hierarchical pyramid person, manager to the lowest level;

- Order - inputs at the right place and the right time;

- Fairness - justice combination with good intentions. Managers should characterize relations with subordinates;

- Staff stability - is a negative fluctuation. Personal job stability is a prerequisite for greater efficiency. High frame fluctuation is cause and consequence of a poor state of affairs. Preferably a less talented manager who does not frequently change work organization is loyal to its operating;

- Initiative - encouraging limitless initiative. The initiative means developing plans and ensuring their fulfillment. This organization gives force and energy;

- Teamwork - the team is a force and it is the result of harmonious existence between team members.

H. Fayol was first stopped believing exclusive privilege management, arguing that it is a particular responsibility of top management only, while demonstrating that management functions exists at all levels in 
the organization and, in some as they are made even workers, the higher up the organizational hierarchy, the greater the responsibility, and vice versa.

H. Fayol management organization approaches the issue from several points of view (Huczynski, Buchanan, 2001):

- In terms of body material - all the instruments of labor, objects of labor and labor itself.

- In terms of the social body - organizing relations between people at work. Deciding every employee so that each employee to be in place.

H. Fayol the organization as a complex organism that divides it into several parts, each part by executing specific operations, such as: technical (production), trade (supply, sale, exchange), financial records (accounting, statistics) security, insurance (Protection of property and persons) and administrative (foresight, organization, coordination, command and control). He stressed the need to maintain harmony in the workforce and teamwork, as shown in Figure no. 1.

According to the author, organizational success depends more on the managerial skills of the managers, rather than their technical skills. Managers must have certain qualities and experience: physical attributes (health, vigor, ability), mental qualities (ability to understand and learn, judgment, logic, mental vigor and adaptability); moral qualities (energy, strength, willingness to accept responsibility, initiative, sense, loyalty, tact, dignity); general education (general knowledge, which does not belong solely to the function performed); special knowledge, particular those relating to commercial techniques, management, etc., such experience (knowledge derived from experience) (Vagu, Stegăroiu, 1998). 
Figure 1. H. Fayol's conception on administrative management.

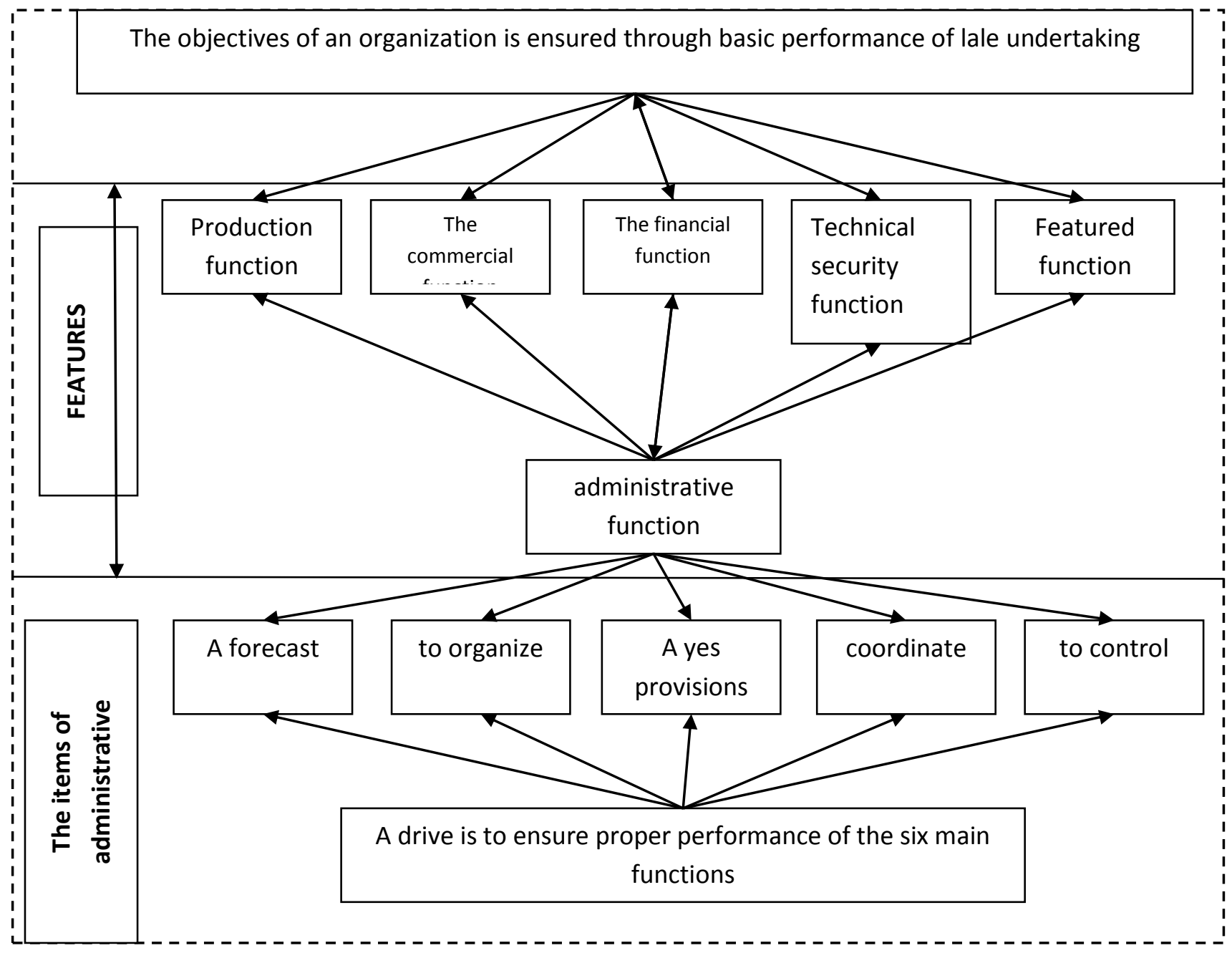

Source: Paraschiv Vagu, Ion Stegăroiu, General Management, Macarie Publishing House, 1998

Harrington Emerson (1853 - 1931) - contributed to promotion principles and methods of scientific management in the business world. He believed that man works more aware when you know the objectives have to be achieved and that management is a profession of faith and philosophy of the organization. Emerson believes that the work efficiency problem can be solved in two ways:

- To be effective workers - have invented methods that would allow people to obtain maximum results that are able to solve similar tasks or goals. To achieve the objectives of employment, workers have a higher efficiency of $60 \%$; 
- Developing ways of targeting employment - which require maximum productivity from those employees who are avaible. This activity is highly inefficient, as workers do not produce even $1 \%$ of its capacity.

One of the fundamental ideas of the author refers to the link between efficiency and organizational structure. He believes that much of ineffectiveness is the result of insufficient organization and the organizational structure that size is not the only factor influencing on efficiency. The author elaborates a series of principles such as:

- Clear and precise objectives and ideals set whose touch tend to each manager and his subordinates - the importance of goals and ideals for the practical work of organizations is hardly overrated and constitutes one of the fundamental principles of management. Ideals managers to be transmitted across organizational structure;

- Addressing efficiency on the principles of common sense in analyzing each new process, taking into account the objectives of perspective - if a businessman lacks goals, organization and common sense, he is not likely to conduct business effectively;

- The need for special knowledge and competent advice on all matters concerning the production and management - no manager can not be competent in all areas to successfully conduct business;

- Subordination of all members of the established rules and order - an activity which aims achieving common objectives is reflected in the cooperation;

- Promoting fair personnel policies, coherent and stimulating - the most difficult problem in ensuring correct behavior in conducting business is achieving a balance between salary and work results.

The reward of labor must be acceptable and maintain better hope for tomorrow. A manager must be characterized by the following quality:

- understanding a community of interests of all employees;

- imagination: a sense of fairness.

- Clear evidence that there is a suitable and permanent and control information necessary to ensure Manager - this principle refers to standards and graphs that can be the result of precise mathematical calculations or can be expressed quantitatively and qualitatively;

- Existence of standardized conditions - author criticizes the tendency to skip the present and future detailed plan relying on techniques and rules of thumb that have operated in the past;

- Good results are not obtained by chance - standardization of operations ensures the likelihood of good results, which means that to achieve a high efficiency sufficient intellectual capacities appropriate, will power and organizational skills, which allow to link actions with standardized requirements; 
- Training workers on permanent operating rules and procedures in the organization - workers receive written tasks they have to perform, the procedures and rules to be applied;

- Use of a system of incentive instruments of each performer for effective work in accordance with the objectives of the organization - it gives the performer the opportunity to exercise functions, become aware of the importance of his work.

\section{Conclusion}

The author has based its principles on the example of not only industrial companies but generally to all areas of productive activity. The concept of productivity or efficiency is fundamental in science management brought by the author; he is the one who raised the question of production efficiency broadly. Productivity always gives maximum results with minimum effort; intensity contrary gives sufficient results, but only under tough conditions. To assess the results of the work, the author believes that certain standards must be used (professional standards) understanding that sets rules are recognized by most contractors. Within these standards is given special attention standardization costs. Efficiency is achieved when the necessary object is properly executed according to an employee in place during required necessary. According to the author effectiveness is based on economic activity and for pay.

\section{References.}

Maxwell, John W., 1998. "Minimum quality standards as a barrier to innovation," Economics Letters, Elsevier, vol. 58(3), pages 355-360, March.

Maxwell, John W., 1996. "What to do when win-win won't work: Environmental strategies for costly regulation," Business Horizons, Elsevier, vol. 39(5), pages 60-63.

Zaborilă C., 2004, The group behaviour in laber places, in Bogathy, Z. (coord). Labor psihology, Polirom Publishing House, Iași.

Vagu P., Stegăroiu I., 1998, General Management, Macarie Publishing House.

S. Robbins, M. Coulter, 2005, Management, 8th edition, Pearson, Prentice Hall. 